\title{
Influence of degree of deformation on welding pore reduction in high-carbon steels
}

\author{
Bernd-Arno Behrens ${ }^{1} \cdot$ Hans Jürgen Maier ${ }^{2} \cdot$ Gerhard Poll $^{3} \cdot$ Ludger Overmeyer $^{4} \cdot$ Hendrik Wester $^{1} \cdot$ Johanna Uhe $^{1}$. \\ Thomas Hassel $^{2} \cdot$ Florian Pape $^{3} \cdot$ Marius Lammers $^{4}$. Jörg Hermsdorf ${ }^{4}$. Stefan Kaierle ${ }^{4}$. Laura Budde ${ }^{4}$. Felix Saure ${ }^{3}$. \\ Maximilian Mildebrath ${ }^{2} \cdot$ Timm Coors $^{3} \cdot$ Mohamad Yusuf Faqiri $^{2} \cdot$ Christoph Büdenbender $^{1}$ (i)
}

Received: 14 August 2020 / Accepted: 3 December 2020 / Published online: 16 February 2021

(c) The Author(s) 2021

\begin{abstract}
Locally adapted properties within a machine component offer opportunities to increase the performance of a component by using high strenght materials where they are needed. The economic production of such hybrid components on the other hand represents a major challenge. The new tailored forming process chain, which is developed within the collaborative research center (CRC 1153) represents a possible solution to produce hybrid components. This is made possible by the use of pre-joined hybrid semi-finished products made from two different steel alloys, which are subsequently formed. The semifinished products can be manufactured for example by means of deposition welding. Due to a thermal mechanical treatment, an overall higher component strength of the joining zone can be achieved. The deposition welding processes can be used to generate a cladding on a base material. During the welding, one of the most difficult tasks is to reduce the amount and size of pores in the joining zone. These pores can reduce the strength in the joining zone of the welded parts. However, additional pores can occur in the intermediate zone between the substrate and the cladding. In the presented study, the influence of the forming process on the closing of pores in the cladding and in the intermediate zone was investigated. Therefore, cylindrical specimen were extracted in longitudinal direction of the welding track by wire-cut eroding. These welding tracks are manufactured by plasma-transferred arc welding of AISI 52100 on a base plate made of AISI 1015. Further, specimens were prepared transversely, so that the base material, the intermediate layer, and the welded material are axially arranged in the specimen. The prepared specimen were checked for pores by means of scanning acoustic microscopy. Subsequently, an uniaxial compression test was carried out with various degrees of deformation and the two specimen designs were examined again for pores. A microstructure analysis was carried out after each step. The investigations show that there is a need for a minimum degree of deformation to reduce pores in the welded material. However, this required plastic strain cannot be achieved in the welded material of the hybrid specimen, which is a result of the homogeneous temperature distribution in the specimen. The homogeneous temperature distribution leads to different flow properties in the specimen, which means that the main plastic deformation is taking place in the base material.
\end{abstract}

Keywords Tailored forming $\cdot$ Plasma transferred arc welding $\cdot$ AISI $52100 \cdot$ Scanning acoustic microscopy $\cdot$ Pore reduction

Christoph Büdenbender

buedenbender@ifum.uni-hannover.de

1 Institute of Forming Technology and Machines, Leibniz University Hannover, An der Universität 2, 30823 Garbsen, Germany

2 Institute of Material Science, Leibniz University Hannover, An der Universität 2, 30823 Garbsen, Germany

3 Institute of Machine Design and Tribology, Leibniz University Hannover, An der Universität 1, 30823 Garbsen, Germany

4 Laser Zentrum Hannover e.V., Hollerithallee 8, 30419 Hannover, Germany

\section{Introduction}

In many industrial sectors, miniaturisation, lightweight design and optimised functional integration are increasing the demands on the components being used. They have to be manufactured at low cost and with high efficiency, while fulfilling various tribological and mechanical properties. In some cases, a resource-efficient manufacturing process is also desired. A simultaneous optimisation of all requirements is rarely possible when using monomaterial components. Therefore, the development and use of hybrid 
components is steadily gaining importance. One innovative hybrid manufacturing concept is the so called tailored forming process chain which is based on the use of a prejoined hybrid semi-finished product in a following forming process [1]. This enables an economic and resource-saving production of parts with locally adapted properties. Material and energy can be saved by combining cost-effective materials, such as structural steel or lightweight materials, with high-strength materials. For the combination of different materials, novel joining techniques and forming processes are used. The tailored forming process can be used, for example, to manufacture shafts, gears or axial bearing washers in a hybrid design [2,3]. The main work steps required to produce components using the tailored forming process are for example the deposition welding of the high strength functional layer on the base material. This provides a hybrid semi-finished product, which is thermo-mechanically improved by a subsequent forming step. In previous investigations it could be shown, that axial bearing washers, which were produced by manufacturing a martensitic chromium-silicon steel AISI HNV3 cladding onto the mild steel AISI 1015 by laser metal deposition by wire and subsequent forming, achieve almost $70 \%$ of the service life of conventional industrial bearings made of the rolling bearing steel AISI 52100. The endurance tests showed that the bearing failed due to pitting while the joining zone was intact [2]. This suggests that the service life of hybrid rolling bearings can be further increased through the use of higher-strength materials. An example of a cladding with AISI HNV3 is shown in Fig. 1. In the cladding manufactured by laser metal deposition with wire, pores could only be detected at the turnaround points. These pores have no influence on the strength of the later component, as they are removed during post-processing. To increase the service life of the hybrid components, the rolling bearing material AISI 52100 is to be welded onto the substrates and investigated. This material has a higher strength and hardness than the substrate material. While AISI HNV3 is one of the standard welding materials and has good welding properties, AISI 52100 is not considered as weldable due to its high carbon content. Initial investigations on the welding of AISI 52100 have shown that the material tends to form pores. Therefore, the aim of this

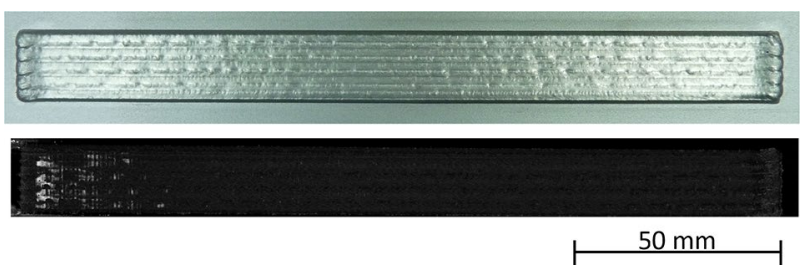

Fig. 1 Laser hot-wire welded AISI HNV3 cladding and corresponding ultrasonic investigation paper is to investigate to what extent the degree of deformation of the subsequent forming process can influence the pores in terms of number, size, position and shape. With these findings, quality requirements for the weld seam can be defined and the process window for the cladding process can be enlarged if necessary. Based on these investigations, the basis for the development of a process chain for hybrid components with AISI 52100 claddings has been provided.

\section{State of the art}

With focus on the welding process the state of the art is presented. Among other aspects, cladding is used to produce a hard, wear-resistant and corrosion-resistant layer, to repair and improve used components and to optimise new components [4]. For this purpose, different processes such as laser metal deposition by wire [2,5], metal inert gas welding, laser metal deposition by powder [5] and plasma powder welding are used. The main materials used for cladding are ceramics, their alloys or a composite of different ceramics [6]. According to [6], pure metals or alloys are used less frequently. Based on a previous work within the Collaborative Research Center 1153 called tailored forming [7], the plasma transferred arc welding is chosen as the welding process. It is characterised by its cladding material, which is applied in powder form. Further benefits are a high degree of automation and reproducibility [8]. The chosen cladding material AISI 52100 is considered non-weldable because of its carbon equivalent of CEV $>1$ according to [9, 10]. Compared to other welding processes, the transfer arc welding process allows a high heat input and high cladding rate. Due to these characteristics, the AISI 52100 can be welded and forms a strong bond with the base material. Another important factor is the availability of the cladding material. Materials in powder form, especially steels with a high carbon content for the application in a bearing, are widely available and can be used with high flexibility in the welding process. Experience in the cladding of steels, especially of non-weldable steels, is rather limited to this day. Kilicay et al. added a protective layer of $\mathrm{FeCrC}$ powder to AISI 5115 steel by plasma transferred arc welding. $\mathrm{FeCrC}$ has a weight percentage of $6.64 \% \mathrm{C}$, which means it is considered difficult to weld. Nevertheless the cladding forms a strong bonding with the base material and reduces the coefficient of friction and wear [11]. Ferozhkhan et al. used plasma transferred arc welding to weld $6 \mathrm{~mm}$ of Stellite 6 alloys on stainless steel to increase the resistance against abrasive wear in high temperature valve applications achieving good results. The cladding layer formed a strong bond with the base material. However, the samples were not specially inspected for defects below the surface [12]. In [13] a WCP/NiBSi-multi-material was manufactured by plasma transferred arc welding with an 
overall hardness of HRC $65 \pm 1$. The bonding between the applied layer and the base material was strong, but intrinsic defects, such as pores and cracks, were formed. Due to the application as a wear protection layer in [14], these defects could be neglected. But this is not permissible for a rolling bearing and the number of defects must be reduced significantly in order to achieve a service lifetime comparable to that of conventional rolling bearings. Pores in the loaded zone cause local stress peaks and can be the starting points for further crack initiation. Studies in [15] show this effect and the increase in the load on the material through pores. However, due to the poor weldability of AISI 52100, defects occur in the cladding and intermediate layer, such as gas inclusions, pores or cracks, which could be reduced by a subsequent forming process. The procedure and results are explained in the following sections.

\section{Material and methods}

\subsection{Plasma-powder-transferred arc welding}

Plasma transferred arc (PTA) welding is a thermal process to obtain various surface properties on metallic components. During the process, a non-melting tungsten electrode creates a plasma arc in order to melt the surface of the workpiece. In the meantime, a powder system inserts the cladding material in the molten welding zone, which results in a substanceto-substance bond after solidification. The welding process is carried out on a six-axis KR 22 industrial robot (Kuka $\mathrm{GmbH}$ ), where two additional axes are realized by a turn and tilt table (DKP 400, Kuka GmbH). The welding torch is a PTR450 (AUTOGEN-RITTER GmbH), which is supplied by the current source PSI 400 (Kjellberg Finsterwalde Schweißtechnik und Verschleischutzsysteme $\mathrm{GmbH}$ ). The experimental setup for the welding process is shown in Fig. 2. The chemical compositions of the base and cladding material are shown in Table 1. The glains of the cladding material have a diamter of minimum $50 \mu \mathrm{m}$ to maximum 200 $\mu \mathrm{m}$ which corresponds to the current industrial standard for PTA welding [15].

Before the welding process starts, the components get sandblasted in order to clean the surface. To start the welding process, the components are fixed on the turn and tilt table, which is aligned in horizontal position. The welding is carried out at room temperature. During the welding process, three lanes are welded overlapping side by side, whereby the lanes form a closed weld seam. Therefore, the welding torch oscillates with an amplitude of $1 \mathrm{~mm}$ and frequency of $1.3 \mathrm{~Hz}$ at an angle of $90^{\circ}$ to the welding direction. The whole welding process takes a total time of $5 \mathrm{~min}$ and $23 \mathrm{~s}$, whereby the sample heats up to a maximum of 650 ${ }^{\circ} \mathrm{C}$. With rising temperatures, also the dilution between the

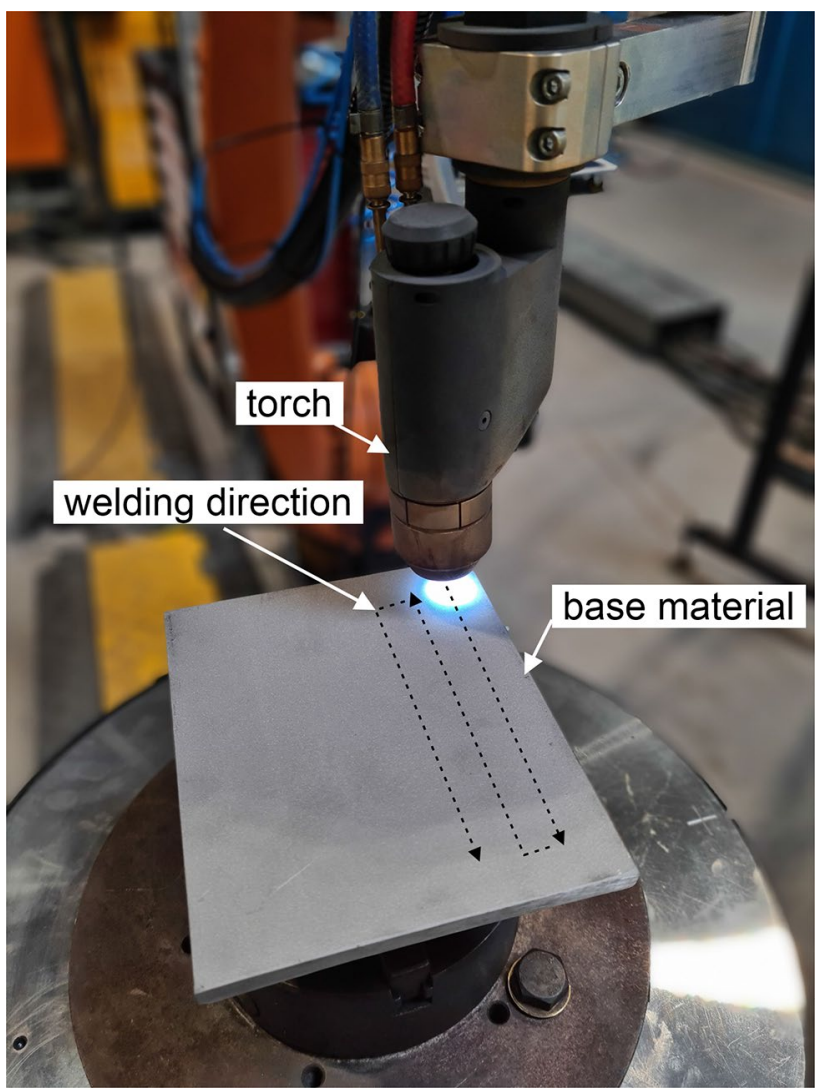

Fig. 2 Experimental setup for the PTA welding process

cladding material and the substrate increases. To counteract the heating a dynamic adjustment of the welding parameters is required. At the beginning a current of $140 \mathrm{~A}$ is selected to generate a fast heating of the sample. In the further process the current is reduced by $10 \mathrm{~A}$ for each following weld seam in order to keep the dilution low and the properties for each seam as constant as possible. An overview of the welding parameters is given in Table 2.

\subsection{Specimen preparation}

In order to investigate the influence of plastic strain on the closing of pores, cylindrical samples of AISI 52100 were taken from the welding track in longitudinal direction by wire erosion and were subsequently compressed. The specimens had a diameter of $5 \mathrm{~mm}$ and a height of $8 \mathrm{~mm}$. The pores in the material were detected before and after the forming investigations by means of scanning acoustic microscopy (SAM).

The area between the base material and the cladding has a high affinity for pore formation during the welding process [7]. In order to investigate the bonding zone, also cylindrical specimens were prepared transversely, so that base material, the intermediate layer and the welded 
Table 1 Chemical composition in wt.\% of cladding material AISI 52100 and base material AISI 1015

\begin{tabular}{lllllll}
\hline AISI & $\mathrm{C}$ & $\mathrm{Mn}$ & $\mathrm{Si}$ & $\mathrm{P}$ & $\mathrm{S}$ & $\mathrm{Cr}$ \\
\hline 52100 & 1.05 & 0.45 & 0.35 & $<0.025$ & $<0.015$ & 1.6 \\
1015 & 0.17 & 1.40 & - & $<0.03$ & $<0.03$ & - \\
\hline
\end{tabular}

Table 2 Welding parameters

\begin{tabular}{ll}
\hline Parameter & Value \\
\hline Shielding gas flow (Argon) & $71 / \mathrm{min}$ \\
Plasma gas flow (Argon) & $1.51 / \mathrm{min}$ \\
Transport gas flow (Argon) & $21 / \mathrm{min}$ \\
Welding speed & $0.078 \mathrm{~m} / \mathrm{min}$ \\
Length of the weld seam & $0.42 \mathrm{~m}$ \\
Current & $140-120 \mathrm{~A}$ \\
Powder material & AISI 52100 \\
Deposition rate & $0.48 \mathrm{~kg} / \mathrm{h}$ \\
Powder mesh & $63-200 \mu \mathrm{m}$ \\
\hline
\end{tabular}

welding track

AISI 52100

(a)

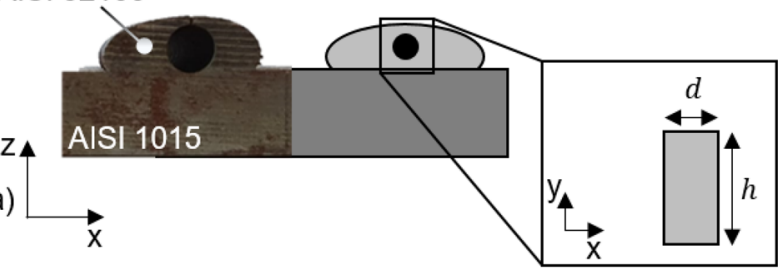

(b)

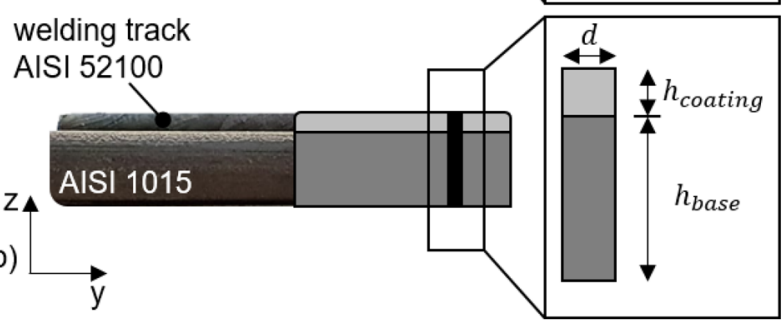

Fig. 3 Specimen preparation a from the welding track in longitudinal direction, $\mathbf{b}$ from the base plate and the welding track transversely

material are axially arranged in the specimen. For the base plates, different heights were used $(10 \mathrm{~mm}, 12 \mathrm{~mm}$ and $15 \mathrm{~mm}$ ) to investigate whether the proportion of the base material has an influence on the overall forming process (Fig. 3)

The height of the welding track was kept constant to $h_{\text {cladding }}=3 \mathrm{~mm}$. This design of the specimens leads to three different kinds of the specimen with different resulting heights $(13 \mathrm{~mm}, 15 \mathrm{~mm}$ and $18 \mathrm{~mm})$. Also a diameter of $5 \mathrm{~mm}$ was chosen for the hybrid specimen.

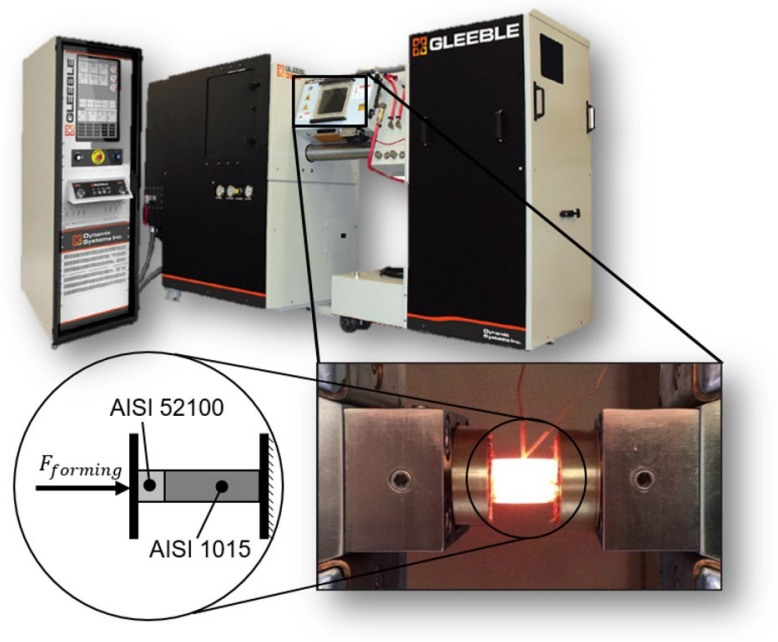

Fig. 4 Gleeble 3800-GTC for the compression tests of hybrid and mono material specimen with the used compress direction

\subsection{Compression test of mono and hybrid cylindrical specimen}

All cylindrical specimens were compressed in the forming simulator Gleeble 3800-GTC by DSI Inc. (cf. Fig. 4). The investigated plastic strains vary from $\varphi=0.3, \varphi=0.5$ and $\varphi=0.7$ to observe the influence of the forming process on the ability to close pores. The temperature for the compression tests was $1100{ }^{\circ} \mathrm{C}$. The test chamber was evacuated during the test to exclude the influence of oxidation. The tests were performed with a strain rate of $\dot{\varphi}=0.1 \mathrm{~s}^{-1}$. In Fig. 4 the orientation of the hybrid specimen is presented. In all tests the cladding is pressed into the base material as depicted in Fig. 4. Graphite was used as a lubricant between the surface of the sample and the forming tool, so that the influence of friction can be neglected. After the two specimen designs were formed, investigations were then carried out with SAM to investigate the influence of plastic deformation on the closing of pores, as previously demonstrated in [7].

\subsection{Numerical model of the hybrid compression test}

To examine the distribution of the plastic strain within the hybrid specimen, an axial symmetric numerical model of the performed compression test was built up with the commercial software Simufact Forming v16. The forming tools 
were modelled as thermally conductive bodies. The friction between the specimen and the forming tool was modelled with the combined friction model, consisting of the Tresca and Coulomb formulation. The parameters of friction were set at $m=0.1$ and $\mu=0.08$, which corresponds to a low frictional behaviour like in the experimental test. An adhesive condition was set between the base material and the welding track material, which cannot be relieved during the forming process. A homogeneous temperature distribution of 1100 ${ }^{\circ} \mathrm{C}$ was assigned to the hybrid samples. An elasto-plastic material model was used to set the material behaviour. The required material data for the base material (AISI 1015) and for the welding track material (AISI 52100) were taken from the Simufact Forming material database.

\subsection{Scanning acoustic microscopy}

Scanning acoustic microscopy (SAM) on a modified PVA TePla SAM 301 system is used for non-destructive testing after sample preparation for experimental investigations, see Fig. 5. For this purpose, an ultrasonic pulse is sent into the sample via a coupling medium, in this case distilled water. To improve corrosion protection, the samples are sprayed with penetrating oil. The interaction at interfaces between different materials, e.g. at defects or material transitions, can be evaluated by analysing the reflected acoustic waves in the run-time signal. An acoustic horizontal sectional image (C-scan) is calculated by scanning the samples line by line using an XY-scanner to which the ultrasound probe (transducer) is attached. Parameters for ultrasonic microscopy are shown in Table 3.

\section{Results and discussion}

\subsection{Properties of the cladding material}

Figure 6 shows SAM images for a typical sample after welding without forming. In level by level orthogonal views, welding defects like pores with a typical size of 20-100 $\mu \mathrm{m}$ and above, can be seen at depths of -0.3 to $-0.9 \mathrm{~mm}$. The slightly pixelated areas indicate signal interference, e.g. due to the surface structure or to the travel speed of the scanner

Table 3 Transducer properties for scanning acoustic microscopy

\begin{tabular}{llll}
\hline $\begin{array}{l}\text { Frequency in } \\
\mathrm{MHz}\end{array}$ & $\begin{array}{l}\text { Focal length in } \\
\mathrm{mm}\end{array}$ & $\begin{array}{l}\text { Axial resolution } \\
\text { in } \mu \mathrm{m}\end{array}$ & $\begin{array}{l}\text { Detection } \\
\text { limit in } \\
\mu \mathrm{m}\end{array}$ \\
\hline 30 & 12.7 & 49.5 & 16.5 \\
75 & 20 & 20 & 6.7 \\
110 & 8 & 13.7 & 4.5 \\
\hline
\end{tabular}

being set to high. Welding defects with a diameter above $20 \mu \mathrm{m}$ were found in 25 out of 40 samples of this set. For further investigations only specimens with pores were used. For samples declared as non-porous, however, it cannot be ruled out that no pores are present below this detection limit.

Figure 7 shows the microsections of the cylindrical samples at different degrees of deformation. All samples have been taken from the same weld seam. Therefore, the metallurgical properties are the same. Figure 7 a shows the initial

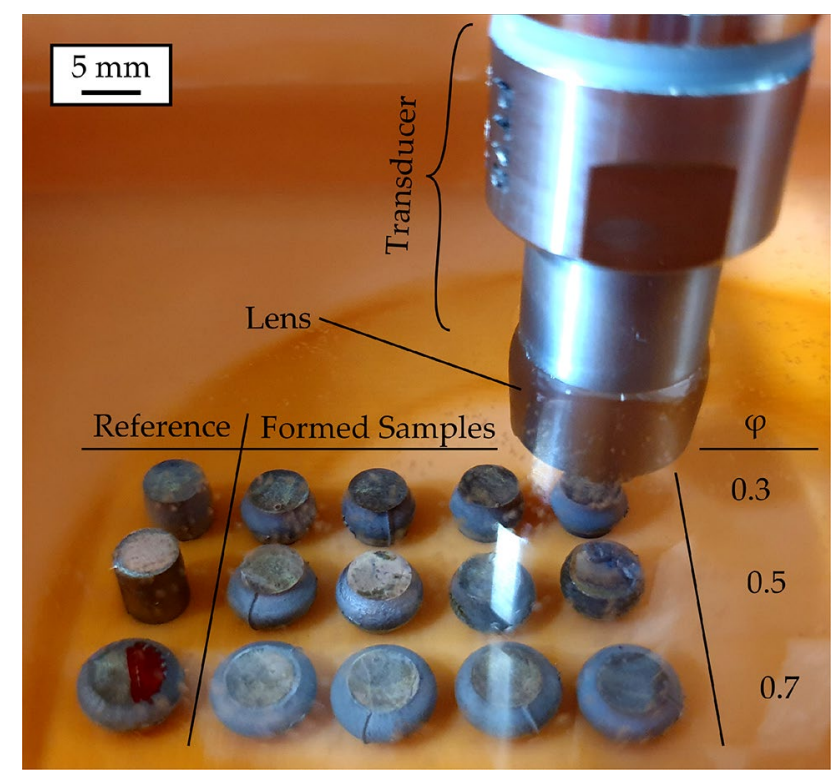

Fig. 5 Scanning acoustic microscopy (SAM) setup with formed samples

Surface

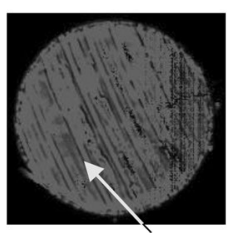

Grinding structure

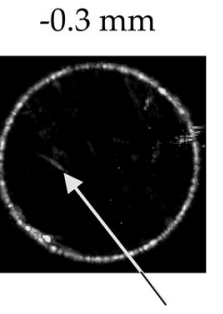

Welding defects

Surface signal interference

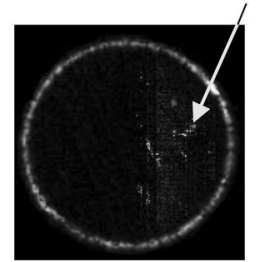

$-0.9 \mathrm{~mm}$

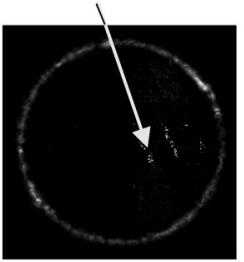

$-1.2 \mathrm{~mm}$
$-0.6 \mathrm{~mm}$
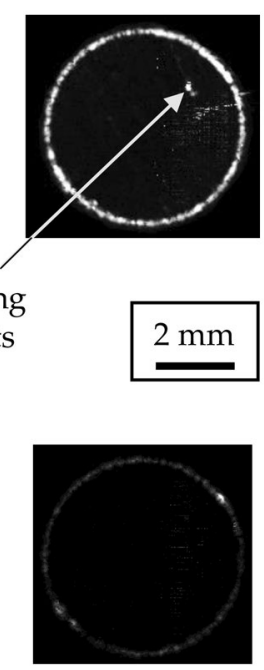

$-1.5 \mathrm{~mm}$
Fig. 6 SAM images of a typical sample after welding $(\phi=0)$ with defects for depths up to $-1.5 \mathrm{~mm}$ from the surface in top view 


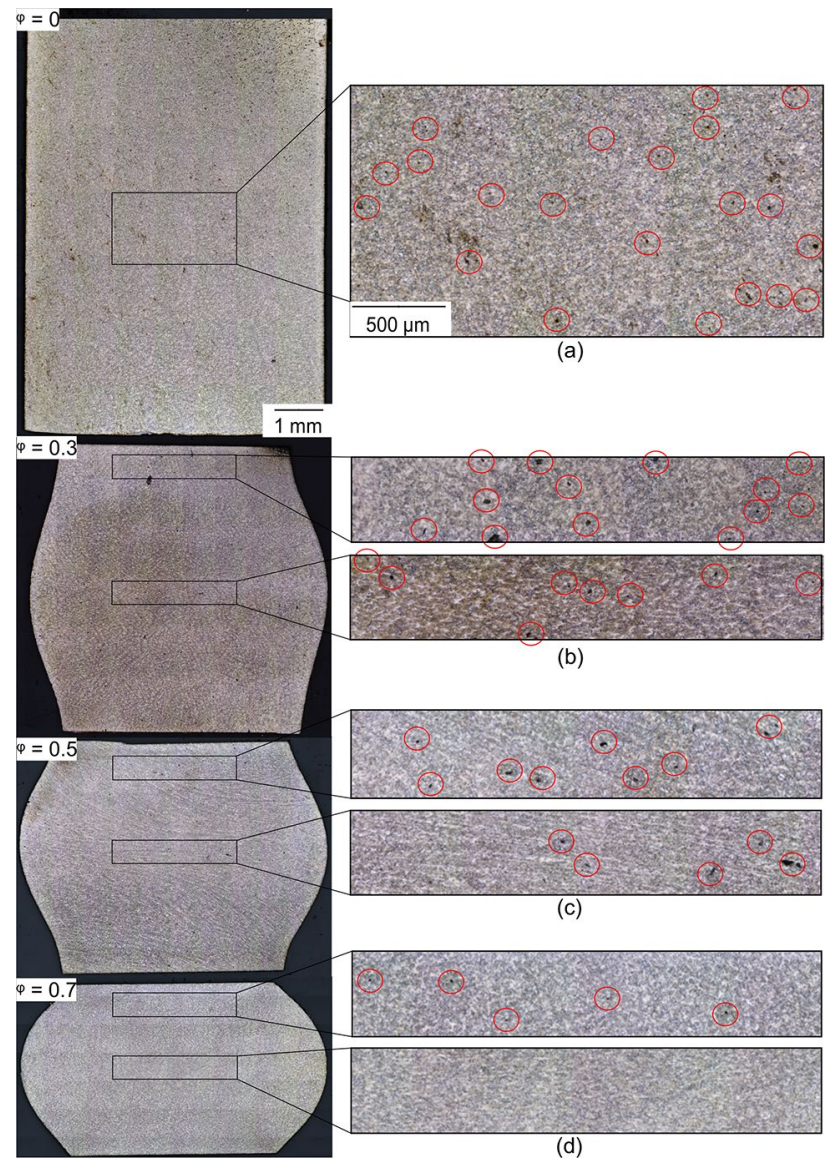

Fig. 7 Axial sections of cylindrical specimen with different degree of deformation $\mathbf{a} \varphi=0, \mathbf{b} \varphi=0.3, \mathbf{c} \varphi=0.5, \mathbf{d} \varphi=0.7$

state of a sample $(\varphi=0)$. An increased number of pores can be identified which appear in form of black dots. The pores are marked with red circles. Figure $7 \mathrm{~b}$ shows the sample for the degree of deformation $(\varphi=0.3)$. There are still pores visible, but less than in the previous Fig. 7a. With increasing degree of deformation, the porosity decreases significantly, as can be seen in Fig. 7c $(\varphi=0.5)$, or disappear almost completely (Fig. 7d, $\varphi=0.7$ ). Due to the higher degree of deformation in the middle of the samples, significantly fewer pores are visible than in the edge areas. The direction of material flow can be seen particularly well in Fig. 7c and d. It can be assumed that above a degree of deformation of $\varphi$ $=0.5$ the porosity is effectively reduced. The SAM images confirm this result. As the degree of deformation increases, the porosity also decreases, which can be seen by a reduction of the white areas.

Figure 8 shows the microstructure images of the respective samples from Fig. 7. Despite the different degrees of deformation, a similar martensitic microstructure prevails in all samples. This is due to the fast cooling of the samples. After forming, the samples cool down very quickly, which results in a martensitic microstructure.

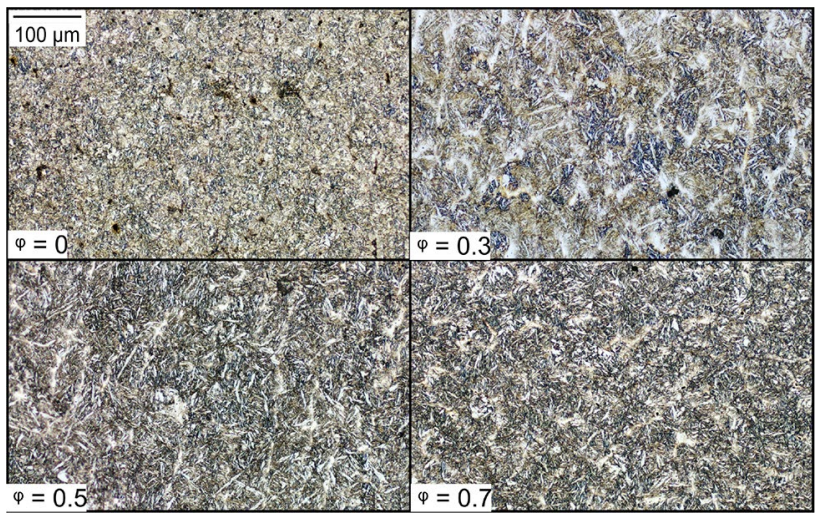

Fig. 8 Detailed view of the microstructure for different degrees of deformation

\subsection{Investigations of hybrid samples}

The results for hybrid samples taken in transverse direction of the specimen are depicted in Fig. 9. As can be seen, for $\varphi=0.3$ larger pores up to $0.5 \mathrm{~mm}$ length are present. With increasing degree of deformation $\varphi$, the overall pore size is reduced. However, even samples with $\varphi=0.7$ are not free of defects. A variation of $h_{\text {base }}$ doesn't seem to have an influence for constant $\varphi$. A total closing of the existing pores is not possible depending on the degree of forming and forming temperature. This is due to gas inclusions existing in the microstructure which cannot leak.

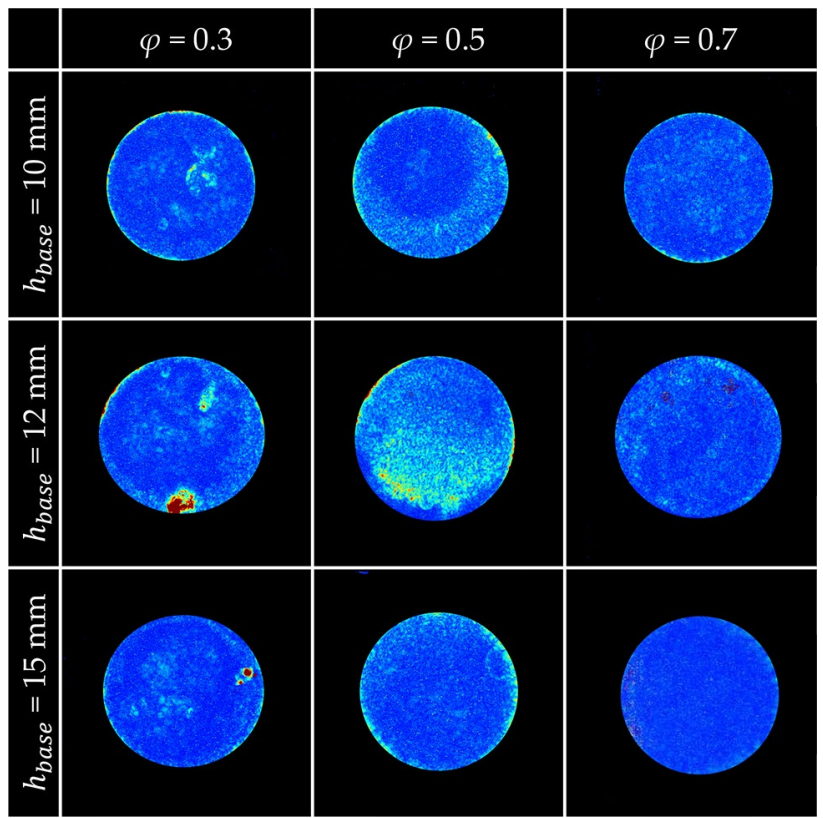

Fig. 9 SAM image matrix for formed samples with $\varphi=0.3$ to 0.7 and $h_{\text {base }}=10$ to $15 \mathrm{~mm}$. Peripheral areas with repetitive echoes were cut out 

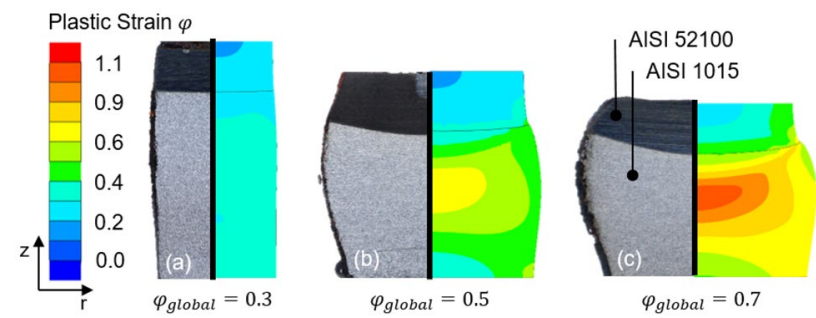

Fig. 10 Comperission of the experimental and compressed hybrid specimen a $\varphi=0.3$ baseplate height $15 \mathrm{~mm}, \mathbf{b} \varphi=0.5$ baseplate height $10 \mathrm{~mm}, \mathbf{c} \varphi=0.7$ baseplate height $12 \mathrm{~mm}$

In Fig. 10, the hybrid specimens are depicted. The results show the situation after a global plastic strain of $\varphi=0.3$, $\varphi=0.5$ or $\varphi=0.7$ was achieved. Figure 10 a show the specimen with a baseplate height of $15 \mathrm{~mm}$, (b) with $12 \mathrm{~mm}$ and (c) with $10 \mathrm{~mm}$.

The results of the numerical investigation of the forming process of the hybrid sample underline the results of the pore analysis results of the hybrid specimen. When considering the degree of deformation distribution of the different sample designs, the following is noticeable: in the intermediate area of the hybrid specimen, a local plastic strain about $\varphi_{\max }=0.56$ was achieved for all three designs of the investigated specimen with a global plastic strain of $\varphi_{\text {global,max }}=0.7$. This indicates that the height of the base plate has no significant influence of the achieved plastic strain in the intermediate area. In the cladding itself a maximum of $\varphi_{\text {local,max }}=0.5$ was achieved independently of $h_{\text {base }}$. From the results of the forming tests of the mono specimens in which it was determined that pores were closed from a degree of deformation $\varphi_{\text {global }}>0.5$, the necessary degree of deformation to close or reduce pores was not achieved in the cladding of the test series with hybrid specimen. This suggets that the pores could not be closed due to an insufficient degree of deformation. The main deformation always takes place in the base material (cf. Fig. 10). This can be explained by the much lower flow stress of the base material compared to the cladding material AISI 52100. Therefore an inhomogeneous heating of the hybrid sample is necessary, so that the flow stress levels are balanced and the cladding can be deformed to a degree of deformation of $\varphi>0.5$ or higher.

Figure 11 shows the stress triaxiality for the three cases, which are identical to Fig. 10. The stress triaxiality represents the well known ratio of hydrostatic stress to von Mises equivalent stress. The results show that a uniaxial or hydrostatic compressive stress is present in both the base material and cladding material. Since the degree of deformation is the only variable parameter in the investigations considered, it seems feasible that a combination of compressive stresses and high degrees of deformation helps to reduce pores in claddings.

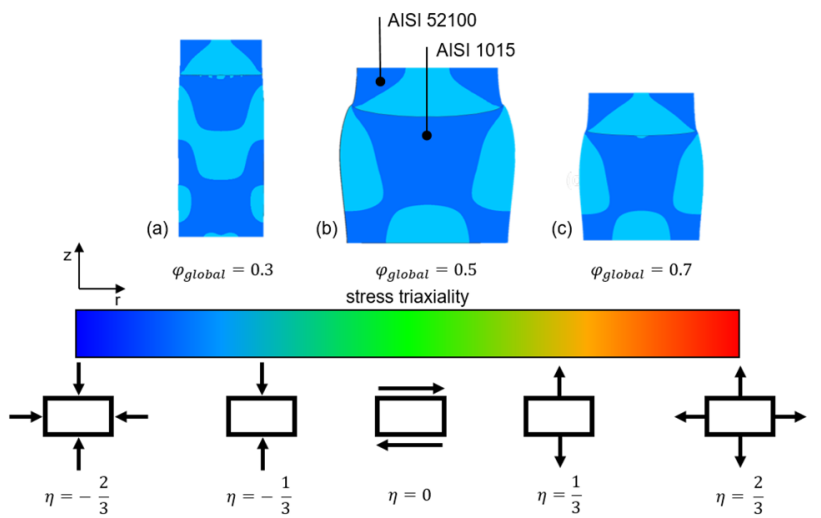

Fig. 11 Representation of the stress triaxiality of hybrid specimen a $\varphi=0.3$ baseplate height $15 \mathrm{~mm}, \mathbf{b} \varphi=0.5$ baseplate height $10 \mathrm{~mm}, \mathbf{c}$ $\varphi=0.7$ baseplate height $12 \mathrm{~mm}$

\section{Summary and outlook}

The present study shows the investigation of the influence of the plastic strain on the closing of pores in mono (AISI 52100) and in hybrid specimen (AISI 1015 and 52100). The hybrid specimen was designed so that the base and the cladding material contained in the specimen. Before and after the compression test the specimens were checked for pores by means of SAM. In the forming investigations, a global plastic strain of $\varphi=0.3, \varphi=0.5$ and $\varphi=0.7$ was chosen. The results of the forming of the mono specimens show that with an increasing plastic strain, the number of pores reduces significantly. From a global plastic strain of $\varphi>0.5$, a reduction of pores can be observed. These results were observed by means of the SAM and a subsequent micro section of the specimens. By a plastic strain of $\varphi=0.7$, the pores disappear nearly completely. A closing of pores in the cladding and in the intermediate zone of the hybrid specimen cannot be observed. The amount of pores is reduced but completely defect-free samples could not be provided by the uniaxial compression test. This is a result of the different material flows within the hybrid specimen, which was investigated by means of a numerical investigation. The results indicate that the maximum achieved plastic strain within the cladding was $\varphi_{\text {local,max }}<0.5$, which is below the plastic strain required to close the pores seen in the forming tests of the mono specimen. Due to the homogeneous heating of the hybrid specimen the flow stress of the base material is much lower than the flow stress of the cladding. Therefore, the main deformation takes place in the base material and the required plastic strain to close pores cannot be achieved in the cladding and in the intermediate layer. To avoid the main deformation in the soft base material, an inhomogeneous temperature distribution within in the hybrid sample is necessary. This could be achieved by induction heating. A suitable temperature distribution can be designed by numerical simulation of 
the induction heating process. In further investigations, the required temperature gradient of the hybrid specimen needs to be calculated by means of the numerical investigation in order to achieve the required plastic strain in the cladding. The aim is to achieve a higher material flow in the cladding by increasing the temperature in this zone. The transfer of inhomogeneous temperature distributions can be realised in industrial processes by an inductive heating method. Here, the heating of the surface layers can be controlled in a targeted manner. The new investigation will be evaluated subsequently by the presented experimental test method. The results will be used within the tailored forming process chain to manufacture high performance components using hybrid semi-finished products. For example the manufacturing of an bearing washer can participate from the findings within this manuscript. Within the tailored forming process chain, the running surface is welded on a base material and formed, subsequently. The results presented indicate that sufficient forming and the presence of uniaxial pressure or hydrostatic stress can reduce welding defects such as pores in the running surface.

Acknowledgements The results presented in this paper were obtained within the Collaborative Research Centre 1153 Process chain to produce hybrid high-performance components by tailored forming in subproject A4, T1, C1 and C3. The authors would like to thank the German Research Foundation (DFG) for the financial support of this project-Grant number 252662854.

Funding Open Access funding enabled and organized by Projekt DEAL.

\section{Compliance with ethical standards}

Conflict of interest The authors declare that they have no conflict of interest.

Open Access This article is licensed under a Creative Commons Attribution 4.0 International License, which permits use, sharing, adaptation, distribution and reproduction in any medium or format, as long as you give appropriate credit to the original author(s) and the source, provide a link to the Creative Commons licence, and indicate if changes were made. The images or other third party material in this article are included in the article's Creative Commons licence, unless indicated otherwise in a credit line to the material. If material is not included in the article's Creative Commons licence and your intended use is not permitted by statutory regulation or exceeds the permitted use, you will need to obtain permission directly from the copyright holder. To view a copy of this licence, visit http://creativecommons.org/licenses/by/4.0/.

\section{References}

1. Behrens B-A, Overmeyer L, Barroi A, Frischkorn C, Hermsdorf J, Kaierle S, Stonis M, Huskic A (2013) Basic study on the process combination of deposition welding and subsequent hot bulk forming. Prod Eng 7(6):585591

2. Pape F, Coors T, Barroi A, Hermsdorf J, Mildebrath M, Hassel T, Kaierle S, Matthias T, Chugreev A, Chugreeva A, Behrens B-A, Overmeyer L, Poll G (2018) Tribological study on tailored-formed axial bearing washers. Tribol Online 13(6):320-326

3. Chugreeva A, Mildebrath M, Diefenbach J, Barroi A, Lammers M, Hermsdorf J, Hassel T, Overmeyer L, Behrens B-A (2018) Manufacturing of high-performance bi-metal bevel gears by combined deposition welding and forging. Metals 8(11):898

4. Schneider M (1998) Laser cladding with powder, effect of some machining parameters on clad properties. Ph.D. Thesis at the University of Twente, Enschede, The Netherland

5. Kaierle S, Barroi A, Noelke C, Hermsdorf J, Overmeyer L, Haferkamp H (2012) Review on laser deposition welding: from micro to macro. Phys Procedia 39:336-345

6. Al-Sayed A, Hussein A-H, Nofa A, Hassab E-S, Elgazzar H, Sabour H (2017) Laser powder cladding of Ti-6Al-4V $\alpha / \beta$ Alloy. Materials. https://doi.org/10.3390/ma10101178

7. Behrens B-A, Chugreev A, Matthias T, Poll G, Pape F, Coors T, Hassel T, Maier H-J, Mildebrath M (2019) Manufacturing and evaluation of multi-material axial-bearing washers by tailored forming. Metals 9:232

8. Schneider W, Twrdek J (2019) Praxiswissen Schweißtechnik, 6th edn. Springer Vieweg, Wiesbaden, p 268

9. Dilthey U (2005) Schweißtechnische Fertigungsverfahren 2Verhalten der Werkstoffe beim Schweißen. Springer, Berlin, p 130. ISBN 978-3540216742

10. Matthes K, Schneider W (2016) Schweißtechnik Schweißen von metallischen Konstruktionswerkstoffen, 6th edn. Hanser Verlag, Munich, pp 33-34

11. Yuan Y, Li Z (2017) Microstructure and tribology behaviors of in-situ WC/Fe carbide cladding fabricated by plasma transferred arc metallurgic reaction. Appl Surf Sci 423:1324

12. Ferozhkhan M-M, Duraiselvam M, Ganesh Kumar K, Ravibharath R (2016) Plasma transfered arc welding of stellite 6 alloy on stainless steel for wear resistance. Procedia Technol 25:1305-1311

13. Liu C, Peng H, Zhao Y, Yuan Y, Guo H-B, Xu H-B (2018) Microstructure, mechanical and corrosion properties of electron-beammelted and plasma-transferred arc-welded WCp/NiBSi metal matrix composites. Rare Met 110:818

14. Narayanan G, Gnanamoorthy R (2007) Rolling/sliding contact fatigue life prediction of sintered and hardened steels. Wear 262:70-78

15. Dilthey U (2005) Schweißtechnische Fertigungsverfahren 1 - Schweiß- und Schneidtechnologien, 3rd edn. Springer, Berlin, p 208

Publisher's Note Springer Nature remains neutral with regard to jurisdictional claims in published maps and institutional affiliations. 